\title{
Advanced adenoid cystic carcinoma of the cervix: a case report and review of the literature
}

\author{
Lalla Kawtar Elhassani ${ }^{1}$, Hind Mrabti ${ }^{1}$, Nabil Ismaili ${ }^{1}{ }^{*}$, Youssef Bensouda ${ }^{1}$, \\ Ouafae Masbah ${ }^{2}$, Imane Bekkouch ${ }^{2}$, Khalid Hassouni ${ }^{2}$, Fouad Kettani ${ }^{3}$ \\ and Hassan Errihani ${ }^{1}$
}

Addresses: ${ }^{1}$ Department of Medical Oncology, ${ }^{2}$ Department of Radiotherapy, National Institute of Oncology, Agdal/Riad, Rabat-10000, Morocco and ${ }^{3}$ Department of Pathology, Ibnsina Hospital, Agdal/Riad, Rabat-10000, Morocco

Email: LKE - elhassani_k@yahoo.fr; HM - mrabti_h@yahoo.fr; NI* - ismailinabil@yahoo.fr; YB - yoss.onco@hotmail.com;

OM - masbahouafae1979@yahoo.fr; IB - bekkiman78@yahoo.fr; KH - khalidhassouni@caramail.com; FK - fouadkettani@yahoo.fr;

HE - h_errihani@yahoo.fr

* Corresponding author

Received: 7 January 2009 Accepted: 24 February 2009 Published: 16 June 2009

Cases Journal 2009, 2:6634 doi: 10.4076/1757-1626-2-6634

This article is available from: http://casesjournal.com/casesjournal/article/view/6634

(C) 2009 Elhassani et al; licensee Cases Network Ltd.

This is an Open Access article distributed under the terms of the Creative Commons Attribution License (http://creativecommons.org/licenses/by/3.0),

which permits unrestricted use, distribution, and reproduction in any medium, provided the original work is properly cited.

\begin{abstract}
Introduction: Adenoid cystic carcinoma is a malignant epithelial neoplasm derived from the salivary glands. Primary adenoid cystic carcinoma of the cervix is extremely rare, accounting for less than $1 \%$ of all cervical carcinomas. In this paper we report a case of primary adenoid cystic carcinoma and a review of the related literature.

Case presentation: A 68 year-old woman was admitted with signs and symptoms suggestive of a cervical cancer. The radiological and pathological investigations confirmed the diagnostic of primary adenoid cystic carcinoma of the cervix at Stage IIIB according to the International Federation of Gynaecology and Obstetrics classification. The patient was managed successfully by concurrent chemo-radiotherapy.

Conclusion: The optimal management of adenoid cystic carcinoma cannot be established for certain. From our case and from the literature, it appears that combined treatment (surgery, radiotherapy, and chemotherapy) is necessary for achieving a long-term remission. Concurrent chemo-radiotherapy appears to be a logical option for locally advanced disease.
\end{abstract}

\section{Introduction}

Adenoid cystic carcinoma (ACC) is a malignant epithelial neoplasm derived from the salivary glands and can occur in a variety of other sites. It is characterized by slow growth and high rate of local recurrence. Metastatic spread is usually a long-term complication [1]. Primary ACC of the cervix is extremely rare, accounting for less than $1 \%$ of all cervical carcinomas [1]. The first case was described in 1949 by Paalman [2]. To our knowledge, only 160 cases have been reported up to 2008. Because of the rarity of the 
disease, no standard treatment has yet been proposed. We report a case of primary ACC of the cervix and we discuss briefly the clinical and therapeutic features of the disease.

\section{Case presentation}

A 68 year-old postmenopausal Caucasian woman (para 10, gravida 10) admitted to our hospital with spontaneous vaginal bleeding for 6 months. The patient had never used oral contraceptives or hormone replacements. Gynaecological examination showed an exophytic ulcerated tumor measuring up to $8 \mathrm{~cm}$ in the largest diameter. The lower third of the vagina was involved by the tumoral process. On bimanual recto-vaginal examination we showed that the tumour had invaded both sides of the parametrium. Pelvic computed tomography (CT) scan showed a heavily cervical mass measuring $6 \mathrm{~cm} \times 10 \mathrm{~cm}$. The cervical biopsy was performed. Histological study of the sampled material showed adenoid cystic carcinoma infiltration (Figures 1 and 2). CT scan of the chest and abdomen was normal. The patient was staged IIIB according to the FIGO classification (classification systems established by the International Federation of Gynaecology and Obstetrics for the staging of gynaecological cancers). She was managed with concurrent chemotherapy and photon $(25 \mathrm{MV})$ external-beam radiotherapy (RT). The total dose of RT was 70 Gy delivered in 2 Gy daily fractions with concurrent weekly cisplatin chemotherapy at a dose of $40 \mathrm{mg} / \mathrm{m}^{2}$ iv for 6 cycles. After the treatment completed, the symptoms disappeared with complete response of the tumour in physical examination and in CT scan. The

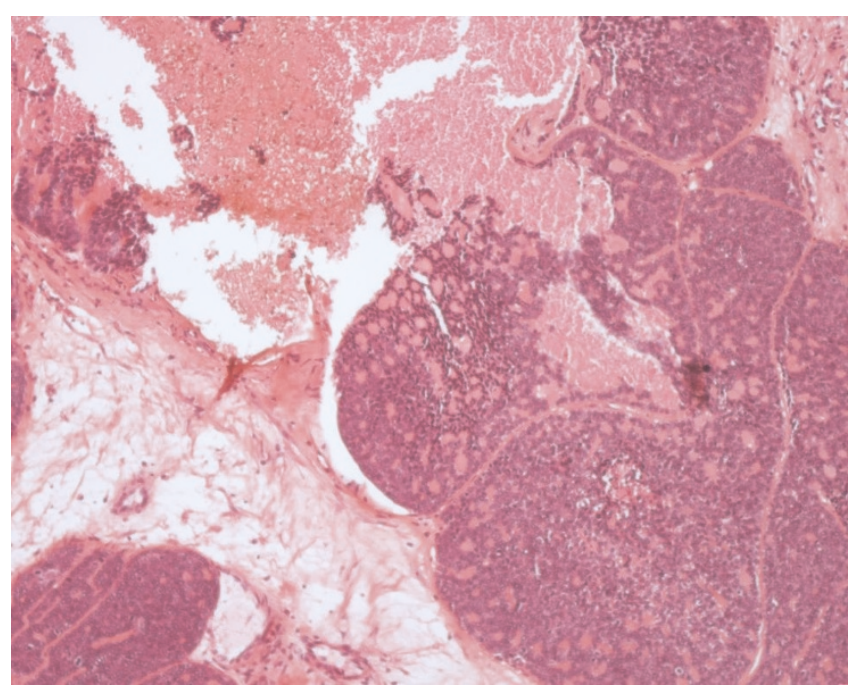

Figure I. Hematoxylin and eosin (HE) staining of the biopsy specimen, low power view: Proliferation composed of small, basaloid cells with trabecular structure. Cylindromatous structures were present. The cribriform pattern was barely seen with large areas of necrosis.

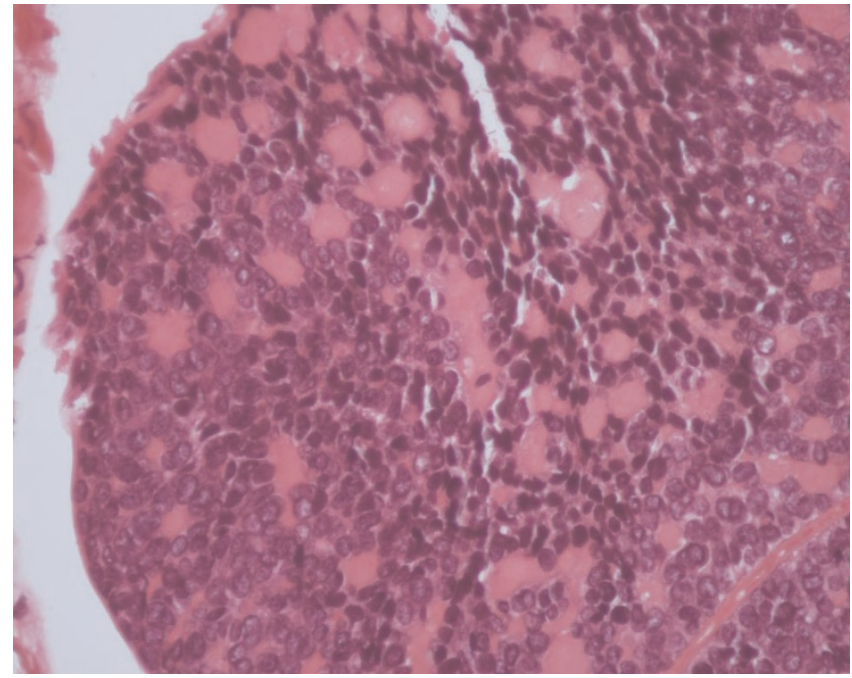

Figure 2. Hematoxylin and eosin (HE) staining of the biopsy specimen, high power view.

patient, 12 months after the end of chemoradiotherapy, remains disease free. She is continuously followed by our group up to now.

\section{Discussion}

We report a case of locally advanced ACC of the cervix a rare malignancy in general. Primary ACC of the cervix accounts for less than $1 \%$ of all cervical carcinomas [1]. The origin of this disease is still unknown. Although, Human papillomavirus (HPV) infection is believed to be a necessary cause of cervical cancer, its role in the pathogenesis of ACC is not well defined [3]. There are some controversies concerning the epidemiological features of this tumor. Our patient was post-menopausal, Caucasian and multiparous woman. ACC of cervix was considered as the disease of the postmenopausal women [4], but more recent data reported some cases in young woman [5-8]. Although, some authors suggested the association between ACC, high parity and black race $[4,9]$, Dixit supported the absence of the observed relationship [10].

Clinical and radiological characteristics of primary ACC of the cervix were similar to those of a squamous cell cancer. The main symptom of disease was the vaginal bleeding [10]. In the review reported by Dix et al, the most majority of patients were diagnosed at early stages, while only 10 cases were diagnosed at stage IIIB and 4 at stage IV [10].

Because of the rarity of the disease and the absence of prospective studies, no standard treatment has yet been proposed. Most patients were treated as squamous cell 
Table I. Clinical findings of majority of published stage IIIB ACC of the cervix

\begin{tabular}{|c|c|c|c|c|c|}
\hline Author & Year & Age & Treatment & Follow-up & Status \\
\hline Gallager [9] & |97| & 64 & RT & 30 months & DOD \\
\hline Fowler [4] & 1978 & 72 & RT & 6 years & DOD \\
\hline Hoskins [6] & 1979 & 40 & RT & 2 months & DOD \\
\hline Prempree [II] & 1980 & 52 & RT & - & DOD \\
\hline Miles [12] & 1981 & - & RT & 9 months & DOD \\
\hline Shingleton [13] & $198 \mid$ & 78 & RT & 2,5 months & DOD \\
\hline Musa [I4] & 1985 & - & RT & II month & NED \\
\hline Berchuck [15] & 1985 & 79 & $\mathrm{RT}+\mathrm{CT}$ & - & Progressive disease \\
\hline Berchuck [15] & 1985 & 72 & RT & 7 months & Peritoneal metastasis \\
\hline Dixit [5] & 1994 & 30 & RT & 48 months & NED \\
\hline Nishida [16] & 2005 & 78 & RT & 5 years & NED \\
\hline
\end{tabular}

Abbreviations: RT: Radiotherapy; CT: Chemotherapy; DOD: Death of disease; NED: No evidence of disease.

carcinoma. Surgery seems to be the treatment of choice in combination with adjuvant radiotherapy and/or chemotherapy, based on the clinical stage and presence of metastasis. Dixit recommended surgery with adjuvant CRT for early stage, and CRT in advanced stage [10]. A large number of chemotherapeutic regimens have been used in disease management. The most used chemotherapeutic drug is CDDP given at dose $100 \mathrm{mg} / \mathrm{m}^{2}$. Other regimens have been investigated, such as bleomycin, adriamycin and 5 Fluorouracil. To our knowledge, our patient is the 13th Stage IIIB of ACC and the first case successfully managed with concurrent CRT. (Table 1) summarizes the clinical findings of majority of published Stage IIIB ACC of the cervix.

ACC of the cervix seems to be more aggressive than squamous cell carcinoma of the cervix, with higher tendency to local and metastatic recurrence even if diagnosed in their earliest stages $[1,17]$. Five years and ten years survival were $37 \%$ and $40 \%$ respectively [18]. These tumours spread most frequently to the lung, lymph nodes, abdominal cavity and brain [10]. The prognostic factors identified were: large tumour diameter, deep stromal invasion, and presence of tumor cells within a lymphatic space or capillary/ blood [19]. Consequently, the authors support the use of multimodality therapy including surgery, chemotherapy and radiotherapy for achieving long term remission [10].

\section{Conclusion}

In the absence of prospective study, optimal management for ACC of the cervix cannot be established for certain. From the literature, it appears that combined treatment is necessary for achieving cure. Radical surgery with adjuvant radiotherapy and/or chemotherapy appears to be a logical option. Concurrent chemo-radiotherapy should also be considered for locally advanced disease.

\section{Abbreviations}

ACC, Adenoid cystic carcinoma; CT, Computed tomography; FIGO, International Federation of Gynaecology and
Obstetrics; MV, Megavolt; RT, Radiotherapy; HPV, Human papillomavirus; CRT, Chemo-radiotherapy; CDDP, Cisplatin.

\section{Consent}

A fully informed written consent was obtained from the patient family for the publication of this case report and accompanying images. A copy of the written consent is available for review by the Editor-in-Chief of this journal.

\section{Competing interests}

The author(s) declare that they have no competing interests.

\section{Authors' contributions}

${ }^{*}$ LKE and NI contributed equally to this work. LKE and NI analyzed and interpreted the patient data regarding the disease history and contributed to the literature research. $\mathrm{HM}$ and $\mathrm{YB}$ and HE contributed to the systemic treatment of the disease. OM and $\mathrm{KH}$ contributed to the section of radiation treatment. FK performed the histological examination of the biopsy of the cervix. All authors read and approved the final manuscript.

\section{Acknowledgment}

We sincerely thanks Mohammed Ismaili, Professor of Microbiology at Moulay Ismail University, Meknes, Morocco.

\section{References}

I. Koyfman S, Abidi A, Ravichandran P, Higgins S, Azodi M: Adenoid cystic carcinoma of the cervix. Gynecologic Oncology 2005, 99:477-480.

2. Paalman RJ, Counseller VS: Cylindroma of the cervix with procidentia. Am J Obstet Gynecol 1949, 58:184-187.

3. Grayson W, Taylor LF, Cooper K: Adenoid cystic and adenoid basal carcinoma of the uterine cervix: comparative morphologic, mucin, and immunohistochemical profile of two rare neoplasms of putative 'reserve cell' origin. Am J Surg Pathol 1999, 23:448-458.

4. Fowler WC, Miles PA, Surwit EA, Edelman DA, Walton LA, Photopuias GJ: Adenoid cystic carcinoma of the cervix. Report of 9 cases and a reappraisal. Obstet Gynecol 1978, 52:337-342. 
5. Dixit S, Singhal S, Neema J, Soornarayan R, Baboo HA: Adenoid cystic carcinoma of the cervix in a young patient. J Postgrad Med 1994, 40:94-95.

6. Hoskins WJ, Averette HE, Ng BP, Yon JL: Adenoid cystic carcinoma of the cervix uteri-report of six cases and review of the literature. Gynecol Oncol 1979, 7:37|-384

7. King LA, Talledo OE, Gallup DG, Melhus O, Otken LB: Adenoid cystic carcinoma of the cervix in women under age 40. Gynecol Oncol 1989, 32:26-30

8. Phillips GL, Frye LP: Adenoid cystic carcinoma of the cervix - a case report with implication for chemotherapy treatment. Gynecol Oncol 1985, 22:260-262.

9. Gallager HS, Simpson CB, Ayala AG: Adenoid cystic carcinoma of the uterine cervix. Report of four cases. Cancer 1972, 27:| 398-| 402

10. Dixit S, Singhal S, Vyas R, Murthy A, Baboo HA: Adenoid cystic carcinoma of the cervix. J Postgrad Med 1993, 39:21I.

II. Prempree T, Villasanta U, Tang CK: Management of adenoid cystic carcinoma of the uterine cervix (cylindroma). Cancer 1980, 46: $1631-1635$.

12. Miles PA, Norris W: Adenoid cystic Carcinoma of the cervix. An analysis of 12 cases. Obstet Gynecol 1971, 38:103-II0.

13. Shingleton HM, Gore H, Bradley DH, Soong S): Adenocarcinoma of the cervix I. Clinical evaluation and pathologic features. Am J Obstet Gynecol I98I, 139:799-8I2.

14. Musa AG, Hughes RR, Coleman SA: Adenoid cystic carcinoma of the cervix - a report of 17 cases. Gynecol Oncol 1985, 22:167-I73.

15. Berchuck A, Mullin TJ: Cervical adenoid cystic carcinoma associated with ascitis. Gynecol Oncol 1985, 22:20I-2II.

16. Nishida M, Nasu K, Takai N, Miyakawa I, Kashima K: Adenoid cystic carcinoma of the uterine cervix. Int J Clin Oncol 2005, 10:1 198-200.

17. Morimura Y, Honda T, Hoshi K, Yamada J, Nemoto K, Sato A: Case of uterine cervical adenoid cystic carcinoma: immunohistochemical study for basement memebrane material. Obstet Gynecol 1995, 85:903-905.

18. van Dinh, Woodruff JD: Adenoid cystic and adenoid basal carcinomas of the cervix. Obstet Gynecol 1985, 65:705-709.

19. Delgado G, Bundy B, Zaino R, Sevin BU, Creasman WT, Major F: Prospective surgical pathological study of disease-free interval in patients with stage IB squamous cell carcinoma of the cervix: a Gynecologic Oncology Group study. Gynecol Oncol 1990, 38:352-357.

\section{Do you have a case to share?}

Submit your case report today

- Rapid peer review

- Fast publication

- PubMed indexing

- Inclusion in Cases Database

Any patient, any case, can teach us something

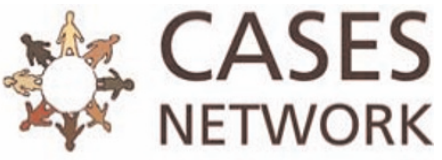

www.casesnetwork.com 